\title{
O drone: considerações sobre a vigilância total e a invulnerabilidade
}

\author{
The drone: considerations on total vigilance and invulnerability
}

Resenha de: CHAMAYOU, Grégoire. Teoria do drone. Tradução de Célia Euvaldo. São Paulo: Cosac Naify, 2015.

\section{Pedro Mateo Bàez Kritski* ; Débora de Sá Ribeiro Aymoré ${ }^{* *}$}

À onisciência corresponde a onipotência

Doutor em filosofia, pesquisador do CNRS - Centre Nacionale de Recherche Scientifique - desde 2010, especialista das obras de Michel Foucault (1926 - 1984) e de Immanuel Kant (1724 - 1804), o filósofo francês Grégoire Chamayou (1976 - presente) parece ter uma preferência pela análise das estratégias que os agentes políticos utilizam para administrar aqueles que estão sob sua tutela. Se na sua tese de doutorado, intitulada Les corps vils: Éxpérimenter sur les êtres humains aux XVIIIe et XIXe siècles (La Découverte, 2008), o autor se concentra na busca do conhecimento como justificativa para o uso desses corpos, em Les chasses à l'homme (La Fabrique, 2010) Chamayou conta a história da transformação e do uso do conceito de "caça" como teoria e prática do uso da força violenta para a dominação de indivíduos.

Os dois primeiros livros nos permitem traçar certa continuidade em relação ao seu terceiro trabalho, intitulado "Teoria do drone" (2015 [2013]), como o resultado da fusão de dois elementos de análise: a relação entre os conceitos de conhecimento e força violenta, que nortearam o seu estudo sobre os modos com os quais os agentes políticos submeteram os indivíduos em dois casos particulares da história. Podemos dizer que em "Teoria do drone" esses conceitos tomam a forma de um objeto real, material. O drone é definido por Chamayou como "[...] câmeras de vídeo voadoras, de alta resolução, armadas de mísseis" Em outras palavras, um “olho-que-tudo-vê" e que também é capaz de projetar força remotamente. A vigilância e a projeção de força materializadas em um objeto que prescinde de um homem embarcado (UCAV - unmanned combat air vehicule) são o mote do livro. O advento de uma tecnologia com tais características traz novos problemas que são explorados pelo autor, dentre os quais destacamos dois: (1) quais são os limites éticos e epistêmicos diante da grande enxurrada de informação gerada pela vigilância, teoricamente ilimitada, que esses objetos voadores oferecem? E, (2) como ficam a legitimação das guerras modernas e o Estado com essa nova forma de projeção de poder?

\footnotetext{
${ }^{1}$ CHAMAYOU, Teoria do drone, p. 47
}

${ }^{2}$ Idem, p. 20

*Doutorando em Filosofia na Universidade de São Paulo, São Paulo, SP. E-mail: pedrokritski@gmail.com ORCID: https://orcid.org/o000-0002-3603-2624

**Professora Substituta de Filosofia da Universidade Federal do Paraná, Curitiba, PR. E-mail: deboraaymore@gmail.com ORCID: https://orcid.org/o000-0003-1384-6681 


\section{A vigilância total}

Os Estados Unidos, segundo Chamayou, possuem mais de 6.000 drones de diferentes modelos e 160 Predators para uso da Força Aérea. A obra também estima que 2.640 a 3.474 pessoas foram mortas entre os anos de 2004 e 2012, no Paquistão. Segundo o autor, a superioridade tecnológica pode transformar a guerra numa prática unilateral, pois ela inibe o risco de morrer enquanto se mata 3 . O prólogo do livro suscita claramente essa imagem no leitor, ao narrar e transcrever partes de diálogos travados entre um operador e um piloto de drone durante uma missão no Afeganistão.

Mas antes mesmo de entrar nos efeitos do uso do drone, é preciso conhecer essa matéria estranha. Ao fazer uma genealogia desse objeto técnico, o autor nos leva para uma breve história do drone, tomando como origem dessa tecnologia a ideia do engenheiro John W. Clark. Segundo Chamayou, em 1965, ao refletir sobre as tecnologias para o enfrentamento de ambientes hostis, Clark apresenta três estratégias: o envio de uma máquina para sofrer a hostilidade, o envio de um homem superprotegido ou a utilização de veículo apropriado ao ambiente hostil. Nesta última opção, o comando do veículo seria feito por um indivíduo em ambiente seguro. A terceira opção, chamada tecnologia telequírica (de manipulação à distância) possui um ganho evidente: retirar do ambiente hostil o corpo biológico vulnerável ${ }^{4}$.

A história avança até a Segunda Guerra Mundial, na qual os drones são utilizados como alvo de treinamento, sendo chamados "drones-alvo" (target drones) pelo exército americano. No final dos anos 1970, os Estados Unidos cessam o desenvolvimento de drones, que foi continuado em outros locais. Como em Israel, que utiliza drones em 1973 no Yom Kippur (no combate contra as forças egípcias) para confundir a defesa inimiga; mesma tática utilizada, em 1982, na guerra contra os sírios, adicionando-se, no entanto, máquinas fotográficas aos aviões aeromodelo como modo de obter informações privilegiadas. Após o 11 de setembro de 2001, o exército dos Estados Unidos começa o uso massivo de drones após armá-los, com sucesso, com de mísseis anticarro5.

O resultado dessa história é que a adição de sensores e de atuadores no que antes era tido como um aeromodelo transforma substancialmente o objeto técnico: o drone amplia capacidades humanas. Com o poder de vigiar por meio da captação de imagens em instantes contínuos ou descontínuos, as câmeras embarcadas de um drone levam àqueles que os possuem mais perto da onisciência. Apesar de serem uma realização limitada do "olho-quetudo-vê”, o drone é capaz de estender o poder de vigilância e de monitoramento.

Detalhando a dimensão desse poder ao leitor, Chamayou divide-o em seis princípios.

O primeiro princípio consiste no que ele chama de princípio do olhar persistente ou de vigília permanente 6 . O drone é capaz de se manter de um modo permanente em uma missão, pois tanto o piloto como o operador podem se revezar em turnos sem que a aeronave precise voltar à base. Aliada a essa persistência, temos o segundo princípio, o princípio da totalização das perspectivas ou de vista sinóptica ${ }^{7}$. Trata-se do poder que esses objetos

\footnotetext{
3 Idem, p. 21

${ }^{4}$ Idem, p. 29

5 Idem, p. $36-37$

${ }^{6}$ Idem, p. 48

7 Idem, p. 48 - 49
} 
possuem de ver tudo, uma vez que o drone carrega consigo dezenas de microcâmeras que permitem a extensão do campo de visão, cuja resolução apresenta uma escala variável.

O terceiro princípio importante para entender a capacidade de vigilância do drone, segundo o nosso autor, é o que diz sobre a capacidade de memória e de interpretação de dados. Descrito por Chamayou como princípio de arquivamento total ou do filme de todas as vidas $^{8}$ esse princípio de vigilância traz a componente do tempo para a onisciência que surge através do uso do drone. Pela possibilidade de arquivar todos os dados de monitoramento remoto, temos, então, o poder de identificação e de controle da vida de indivíduos pela estocagem, indexação e análise das informações coletadas.

Toda tecnologia traz uma nova capacidade aos seres humanos, tais capacidades podem conduzi-los aos seus limites. Um problema relacionado ao grande poder de levantamento de dados é, justamente, quem irá interpretá-los. Como dar sentido aos dados brutos? Chamayou considera que a investigação desse tipo de problema já está em curso, na direção de construir "[...] sistemas cognitivos integrados para a vigilância automatizada"9. Isto é, há pesquisas direcionadas para a produção de "máquinas escribas", que façam esse trabalho cognitivo de um modo automatizado. No futuro, segundo o autor, teríamos sistemas capazes de interpretar, filtrar e indexar dados, antecipando e mesmo facilitando o trabalho de pesquisa sobre as vidas registradas nesses extensos bancos de dados coletados pelos drones.

Sobre a vigilância permitida pelo uso do drone, ainda precisamos detalhar o quarto e o quinto princípios. No quarto princípio, a imagem é apenas um modo de obter informação. Dado que o drone é capaz de embarcar sensores que emulam os outros sentidos humanos, temos o princípio da fusão de dados ${ }^{10}$. O poder de onisciência do drone é composto por ouvidos e muitos outros órgãos análogos aos sentidos humanos. Isso leva ao problema da relação entre dados de naturezas distintas. Pois, enquanto os seres humanos muitas vezes esquecem boa parte das informações que obtém por meio dos sentidos, as informações coletadas pelos drones não perecem e, com isso, permitem a sua fusão com informações de outras fontes. Essa fusão de dados constitui a base para a composição dos padrões de comportamento e dos desvios realizados pelos vigiados, seja um indivíduo ou uma coletividade.

Naturalmente, ao princípio da fusão de dados, adiciona-se o princípio da esquematização das formas de vida ${ }^{11}$ que visa, basicamente, construir patterns of life com os dados coletados dos alvos da vigilância. A relação de dados espaço-temporais - com cronogramas que contém a localização, o deslocamento, os itinerários e os acidentes - é fundamental para o desenvolvimento de uma cartografia das vidas humanas. Com essa combinação de "onde" e "quando" os bancos de dados seriam úteis não somente para perseguir suspeitos, mas também para identificar novos elementos através de comportamentos fora do comum. Isto é, levantam-se dados para formar padrões e formamse padrões para detectar mais facilmente as anomalias e os desvios de comportamento.

Finalmente, a detecção de anomalias compõe o sexto e último princípio da vigilância do drone. O chamado princípio de detecção das anomalias e de antecipação preventiva ${ }^{12}$, que

\footnotetext{
${ }^{8}$ Idem, p. 49

9 Idem, p. 51

${ }^{10}$ Idem, ibidem

${ }^{11}$ Idem, p. 52

${ }^{12}$ Idem, p. 53
} 
mostra o grau de vigilância permitido por esse objeto. A padronização de comportamentos por meio do levantamento de dados permite uma categorização entre o que é normal e do que é anormal. Com o conhecimento do passado comportamental dos indivíduos, é possível agir a partir do que se entende como o futuro das suas ações. E, assim, esse tipo de vigilância traz consigo uma vontade de antecipação, uma ação preventiva guiada por padrões referenciados em grandes bancos de dados. Ao invés de decisões humanas, transferem-se, ao que parece, a decisão ao "olho-que-tudo-vê" e que passa a ser tratado também como o que tudo sabe.

\section{Invulnerabilidade? Efeitos na guerra e no Estado}

Segundo Chamayou, na guerra tradicional, ou seja, sem uso de drones, há relação de reciprocidade: as duas partes envolvidas estimam perdas de efetivo. O drone, no entanto, projeta poder sem projetar necessariamente vulnerabilidade. Mesmo distante de suas fronteiras, é possível aumentar o poder de alcance das armas de telecomando, ao mesmo tempo em que se mantém o operador e o piloto em local protegido, distantes do local das operações. O telecomando possibilita a distância segura, que garante a invulnerabilidade.

Uma questão incontornável que é posta ao leitor do livro é a seguinte: se a guerra pressupõe a projeção de poder e de vulnerabilidade das partes envolvidas, que tipo de relação se estabelece quando se projeta apenas o poder, e não a vulnerabilidade? A resposta inicial de Chamayou é chamar esta situação de guerra unilateral. Porém, ao longo da obra a sua resposta se radicaliza ao ponto de denominar o uso de drones como meio para um homicídio fora de combate ${ }^{13}$.

Como dispositivo tecnológico, o drone altera não somente as relações entre os combatentes, mas também, e ao mesmo tempo, as relações entre a sociedade e o Estado. Tradicionalmente, a relação que o Estado entretém com os seus cidadãos muda conforme se encontre em estado de paz ou de guerra. Em estado de paz, a vida dos cidadãos depende do Estado. E, no estado de guerra, considerado como meio para retomar o estado de paz, o Estado expõe a vida dos cidadãos ${ }^{14}$. E é nesse ponto que a invulnerabilidade do indivíduo transferida para o coletivo gera efeitos surpreendentes.

Com o drone, Chamayou nos lembra, temos uma resposta possível ou ao menos uma alternativa para essa antiga questão que se coloca com a inversão do protego ergo obligo, dos tempos de paz, para o obligo ergo protegor, do estado de guerra: “[...] sabendo que quando o soberano expõe a vida de seus súditos na guerra não os protege mais, em que base ainda pode fundar o dever de obediência de seus súditos?"15. A tendência da "dronização" atribui segurança ao Estado liberal, ou seja, a capacidade de "[...] conciliar a restrição liberalsecuritária das finalidades da soberania do Estado com a manutenção de suas prerrogativas guerreiras. Fazer a guerra, mas sem sacrifício"16.

No entanto, no século XXI, a necessidade de preservação do combatente é reforçada pela criação dos dispositivos telecomandados. Se na Inglaterra do século XIX o pacifismo democrático encontrou no alistamento de indianos como novo meio para fazer a guerra sem custos para o cidadão inglês, evitando assim “[...] sacrificar vidas nacionais no altar do

\footnotetext{
${ }^{13}$ Idem, p. 174

${ }^{14}$ Idem, p. 195

${ }^{15}$ Idem, p. 196 - 197

${ }^{16}$ Idem, p. 198
} 
império"17, o drone, nos tempos contemporâneos, permite o militarismo democrático em outro patamar, ou seja, a guerra com os seus custos virtualmente eliminados pelo advento da máquina de guerra capaz de projetar invulnerabilidade.

Com os riscos sócio-políticos transferidos para o drone, toma-se em conta o impacto dele nas "[...] ferramentas da teoria econômica da decisão. Se o comandante-chefe democrático for por hipótese um agente racional, quais serão os efeitos dessa arma low cost em seu cálculo?"18. Segundo o autor, há uma tripla redução de custos no uso dos drones: a redução dos custos políticos, econômicos e éticos ou políticos, considerando os efeitos sentidos pela violência comedida ${ }^{19}$. Em certo sentido, com o drone, é mais barato ir à guerra.

A redução dos custos de guerra, por sua vez, acaba por fundir ambições de Estado e as ambições de mercado. E com essa fusão do "preservar o capital eleitoral" com o "vender novas armas" ${ }^{20}$, o poder de barganha que os trabalhadores possuíam no começo do século XX e durante a guerra fria vê-se solapado juntamente com muitas das vantagens econômicas e sociais obtidas pela independência do Estado em relação aos corpos humanos.

Deste modo, o drone é objeto central em um momento em que, segundo Chamayou, "[...] a história do Welfare State articula-se à do Warfare State"21. No caso dos Estados Unidos, em que parte significativa de sua população jovem permanece inapta para o serviço militar, o conflito armado passa por duas soluções: um reinvestimento do exército em material humano ou uma independência maior do exército com relação à mão de obra humana. O drone aparece como via para a segunda opção, tornando-se um: "Fazer a guerra sem pôr em risco a vida de seus próprios indivíduos. Conservar sem perder. Proteger, sempre"22.

As consequências políticas do uso desses objetos técnicos, para Chamayou, o fazem parte de uma das etapas de um sonho maior, ou de um desejo prático e real, de fabricação de “autômatos políticos”. O autor entende que a crença é de que, com a automatização, há perda da subjetividade humana pela distância do agente político possível pela máquina "Nesse modo de dominação, que procede pela conversão de suas ordens em programas e de seus agentes autômatos, o poder, que já era distante, passa a ser inapreensível. Onde está o sujeito no poder?" 23 . Para o autor, o sonho é de um poder sem corpo, concretizado pela imagem do robô. "O sonho é construir uma força sem corpo, um corpo político sem órgãos humanos - em que os antigos corpos arregimentados dos sujeitos teriam sido substituídos por instrumentos mecânicos que seriam, em rigor, seus únicos agentes" 24 .

\section{Questões Finais}

Ao ler a obra "Teoria do drone" não se percebe somente a história de um objeto técnico-militar, que aos poucos se torna financeiramente acessível para além das situações de guerra. A obra retrata muito bem as histórias de ideias e de vontades humanas que se cruzam ao serem veiculadas e potencializadas por esse meio técnico-militar de ação. No limite, o drone representa o desejo de concretização, pela via da técnica, de uma vontade de

\footnotetext{
${ }^{17}$ Idem, p. 204 - 206

${ }^{18}$ Idem, p. 207

${ }^{19}$ Idem, p. $207-208$

${ }^{20}$ Idem, p. 212

${ }^{21}$ Idem, p. 213

${ }^{22}$ Idem, p. $213-214$

${ }^{23}$ Idem, p. 228

${ }^{24}$ Idem, p. 242
} 
poder. Com origem na própria sociedade, esse ser criado tende a se diferenciar dela e a afetar sensivelmente as suas características essenciais. Uma via tecnológica para o antigo desejo humano da onisciência e da onipotência.

Finalmente, é possível pensar a atualidade da obra. As declarações de guerra contra um "inimigo invisível”, recorrentes nos discursos jornalísticos e políticos desde a declaração da pandemia gerada pela SARS COVID-19, denotam a vontade da sociedade pela adoção de meios de ação eficientes, orientadas pela tecnociência. Diante de uma doença que ameaça a espécie humana, expondo a vulnerabilidade, encontramo-nos talvez em mais um dos limiares entre a tecnologia de vigilância, seus usos e as suas consequências. 